\title{
Problems and challenges for oral medicine faculties in India
}

\author{
Sumit Bhateja ${ }^{1 *}$, Geetika Arora ${ }^{2}$ \\ ${ }^{1}$ Head, ${ }^{2}$ Reader, ${ }^{1}$ Dept. of Oral Medicine \& Radiology, ${ }^{2}$ Dept. of Public Health Dentistry, Manav Rachna Dental College, Haryana, \\ Faridabad, Haryana, Inderprastha Dental College, Sahibabad, Uttar Pradesh, India
}

*Corresponding Author: Sumit Bhateja

Email: bhateja.sumit@gmail.com

\begin{abstract}
The contents of this article are based on my personal experiences sand are intended to point out issues I feel that, if addressed, will significantly improve the current standards of oral medicine education in India.
\end{abstract}

Keywords: Oral medicine, Faculty, Challenges.

\section{Introduction}

The American Academy of Oral Medicine (AAOM) defines the field as the specialty of dentistry that is concerned with oral health care of medically compromised patients and with the diagnosis and non surgical management of medically related disorders or conditions affecting the oral and maxillofacial region.

Oral medicine specialists referred to as 'oral physicians' are concerned with the non surgical medical aspects of dentistry. The practice of oral medicine will provide optimal health to all people through the diagnosis and management of oral diseases.

Fundamentals to this vision are the following:

1. Recognition of interaction of oral and systemic health.

2. Integration of medical and oral health care.

3. Management of pharmacotherapeutics necessary for treatment of oral and systemic diseases.

4. Investigation of the etiology and treatment of oral diseases through basic science and clinical research.

5. Research, teaching and patient care.

6. Provision of care for medically complex patients and that undergoing cancer therapy.

7. Prevention, definition and management of the following disorders:
a. Disorders of oral mucosa
b. Salivary gland disease
c. Orofacial pain \& other neurosensory disorders

\section{Career paths that oral medicine doctors have followed} include

1. Private practice

2. Hospital based dentists

3. Department chief 's / Dean's at dental schools, medical schools and hospitals

4. Director of residency programs (general practice and oral medicine residency programs)

5. Editors of national and international dental journals

6. Researchers at dental schools, medical schools and other institutions

7. Faculty at medical/dental schools and cancer centers
Discussion of each of career goals / paths is beyond the scope of this essay. Now in the following section I will discuss the problems \& challenges faced by Faculty members of Oral Medicine. The dental faculties play a huge role in shaping the future of dental education in India.

The recommendations made in this essay are based on my educational experiences in India. The issues raised here may not be generalized to all dental schools in India, but I believe that a significant number of those schools face these challenges.

I have listed them priority wise, as per my own judgment.

\section{Problems \& Challenges faced}

1. Priority one: "Over population of Oral Medicine postgraduates"

This frustration is high among Oral Medicine faculty as they see it actually happening in their respective geographic communities. Some are facing bankruptcy and others have gone bankrupt in recent months. In some locations (mostly metro cities like Delhi, NCR, Bangalore, Mumbai, Chennai) oral medicine faculty cannot find employment. Postgraduates feel helpless to overcome the looming problem of overpopulation. Dental leaders need to study the overpopulation situation immediately and make corrections to avoid the problems seen historically with overpopulation. Stiffer standards for school accreditation and more leadership interaction and guidance with new schools planning to start M.D.S program in Oral Medicine are in order.

\section{Priority Two: "Problem of Part time/ Visiting \& On paper Faculty"}

This is one of the challenges that appear to have minimal possibility to be overcome. It is apparent to respondents, despite most of them not being in academic dentistry, that the shortage of Oral Medicine educators is a challenge.

It is no mystery that salary limitations are one of the reasons, combined with the fact that most dentists really want to practice and not teach. This challenge has always been present. It appears that an overt expansion into use of more part-time/ on paper faculty, who do not demand significant salaries is one of the main reasons that the standard of oral medicine teaching has gone down. And 
doctors who really have passion for teaching are not getting full time teaching jobs because of these phantom faculty recruitments.

The Dental council of India together with IAOMR should make some strict norms \& also identify such faculties \& debar them for entering into academics. Plus the managements of such schools should not entertain any such arrangements, and then only problem of shortage of jobs for qualified oral medicine faculty who want to teach as full time faculty will be solved.

Need for More Help from the Profession for fresh pass outs to Start Academic career- Plight of new pass out Postgraduates could be somewhat reduced if the large leadership academies in the profession assumed the mentoring of new postgraduates on an organized basis. What if the IAOMR assumes responsibility of placement of fresh postgraduates in dental schools in India? As a result more and more dentists will be encouraged to take a PG seat in this subject.

\section{Priority Three: "Lack of Qualified Educators"}

While most faculty members have completed a master's program concurrent with residency training in a dental specialty, most of them lack intense research training or a Ph.D. Moreover, most dental schools in India do not have formal tenure-track positions, which typically mandate that faculty members conduct research, publish in peer-reviewed journals, and obtain grants. Consequently, most faculty members in India do not pursue research, nor do they encourage their students to pursue research. Faculty members should be encouraged by the government of India and the Dental Council of India to obtain Ph.D.-level training and should be provided with scholarships to get the training abroad. Apart from the need for better-qualified educators, there is enormous need for improving the teaching methods of current faculty members in Indian dental colleges.

In the United States, faculty members and clinical instructors are evaluated by their students at the end of each course, and these evaluations are taken very seriously. This type of evaluation is definitely important and is missing in the current dental education system in India. Adding an evaluation system will help pave the way for improvements in teaching by the current educators.

\section{Priority Four: "Lack of Funding for Research} Activity"

There is very minimal research activity in undergraduatelevel dental programs in India. The curriculum is so focused on classes and clinics that the students hardly have time to conduct research. Lack of infrastructure, inadequacy of funds, and lack of research mentors are some of the other reasons for minimal research activity among students in dental schools in India.

Almost all the faculty positions in India are teaching positions with very little or no scope for conducting research. The government of India and the Dental Council of India (DCI) should recognize the need for dental research institutes and research blocks in each dental college. Going through the process of conducting research will help not only students but to mentor faculty as well, thus gaining logical reasoning skills \& updating their knowledge that can be directly applied in clinical dentistry. Therefore, a research component should be a requirement in the undergraduate dental curriculum. This would help produce academic leaders with strong research potential and not just teachers in order to make a change in the future of dental education in India.

5. Priorty Five: "Lack of Sufficient knowledge \& proper Hands on training in Advanced radiographic techniques"

Every dental college must have a CT, MRI, Ultrasound \& Digital full body \& extra oral machine so that postgraduate students can benefit from them. Due to lack of such facilities in most of the dental colleges postgraduates of OMR after passing out who turn out to be faculty at dental schools are never confident in these areas \& who will then never be able to impart knowledge/guide their students as well.

6. Priority Six: "Lack of adequate training in Radiotherapy \& Chemotherapy of Oral Cancer"

The MDS curriculum must include training in radiotherapy $\&$ chemotherapy of oral cancer. The DCI should bring these treatment modalities under purview of oral medicine; this will not only expand the scope as well as the pride of our profession. Thus in turn new job opportunities will also be created for oral physicians.

\section{Priority Seven: "Dental Student's attitude"}

This is one of the big challenges what we as a faculty members encounter is lack of interest of students in our subject. Such people after passing out who do not have interest in their profession will never respect their profession.

In India a select group of students enter postgraduate dental education following nationwide or statewide competitive entrance examinations. Typically, some meritorious students who fail to gain admission into more sought after Clinical branches by a small margin enter into academic branches, especially in government-aided dental colleges. Students occasionally are forced to join oral medicine subject because their ranking in the entrance examinations was not high enough to secure a clinical subject seat or because of financial constraints that preclude them from joining private dental schools, which charge high tuition and fees for clinical branches.

This is not a healthy scenario as the students are thus forced to accept a career path that is going to be their profession for the rest of their lives. Administering a separate entrance exam for individuals interested in becoming oral medicine specialists is one solution to this problem. A separate exam would allow students who are really interested in oral medicine to attend one of the dental colleges based on their ranking in an exam specific to that profession.

\section{Priority Eight: "Poor coordination of triple ' $O$ 's faculty"}

In most of colleges there is always a battle for special cases among Oral Medicine, Oral Surgery \& Oral Pathology 
faculty members. Everyone wants to bell the cat \& this all fight is mainly for publication of these cases. Faculty members must share patient's case history, photographs of lesions as well as clinical procedures and of histopathology specimen with each other for better patient management \& care.

There should some Triple $\mathrm{O}$ symposium monthly among faculty members at their respective college levels to discuss treatment modalities \& prognosis of special cases.

\section{Priority Nine: "Publication Ethics"}

It has been seen that in order to attain publication points for promotions, some of our people have been resorting to unethical practices. Equally responsible are the journals who publish unscientific papers of such faculty members after taking hefty amount of money in lieu of publication/ processing charges.

I appeal to DCI \& IAOMR in taking strict actions against such fraudulent journals \& faculty members. Otherwise Indian research scholars will never be graded at par with the international standards.

\section{Priority Ten: "Lack of interest in attending} Continuing Education Courses"

As is evidenced by a low priority assigned to this topic, some may not recognize the severity of this challenge. Young postgraduates are not attending CE courses as frequently as previous generations of oral physicians have attended. They are more interested in online presentations. The result is a diminished amount of social/professional interaction between young and older faculty. One of the topics described above, helping young postgraduates get started in their academic career, should include this point. Older faculty members should encourage younger generation to go to $\mathrm{CE}$ courses with them to assist the young M.D.S in furthering their education. Equally important, such interaction will show young M.D.S the value of live CE and interaction with peers.

\section{Conclusion}

India with its growing population and economy is challenged by a low dentist-to-population ratio and also the current dental education model. It may not be pragmatic to implement all of the recommendations in this essay, but it is time that the Dental Council of India and the IAOMR should revisit the dental accreditation criteria and oral medicine education curriculum and make realistic changes in order to create not just good postgraduates but also leaders in the field of oral medicine able to meet the needs of its growing population.

\section{Source of funding}

None.

\section{Conflict of interest}

None.

\section{References}

1. Greenberg MS, Glick M, editors. Burket's oral medicine, diagnosis and treatment. $10^{\text {th }}$ edition. Ontario: BC Decker Inc, Elsevier; 2003.

2. Brown RS, Silverman S Jr, Hall EH. The oral physician: how do we get from here to there? Dent Today 2001;20:8-11.

3. Bhateja S, Arora G. Oral Medicine: Emergence of a specialty. J Oral Sign 2013;5(1):28-30.

4. Elangovan S, Allareddy V, Singh F, Taneja P, Karimbux N. Indian Dental Education in the New Millennium: Challenges and Opportunities. J Dent Educ 2010;74:9.

How to cite this article: Bhateja S, Arora G. Problems and challenges for oral medicine faculties in India. $J$ Oral Med, Oral Surg, Oral Pathol, Oral Radiol 2019;5(3):77-9. 